\title{
Splenic rupture following colonoscopy
}

\author{
Juan Francisco Guerra, Ignacio San Francisco, Fernando Pimentel, Luis Ibanez
}

Juan Francisco Guerra, Ignacio San Francisco, Fernando Pimentel, Luis Ibanez, Departamento de Cirugía Digestiva, Pontificia Universidad Católica de Chile, Marcoleta 367, Santiago 8330024, Chile

Author contributions: Guerra JF designed the paper, collected and analyzed the data and wrote the manuscript; San Francisco I collect the data and reviewed the manuscript; Pimentel $\mathrm{F}$ and Ibanez $\mathrm{L}$ approved the final version of the manuscript. Correspondence to: Juan Francisco Guerra, Departamento de Cirugía Digestiva, Pontificia Universidad Católica de Chile, Marcoleta 367, Santiago 8330024, Chile.jfguerra@uc.cl

Telephone: +56-2-3543870 Fax: +56-2-6382793

Received: April 9, 2008 Revised: October 14, 2008

Accepted: October 21, 2008

Published online: November 7, 2008

\begin{abstract}
Colonoscopy is a safe and routinely performed diagnostic and therapeutic procedure for different colorectal diseases. Although the most common complications are bleeding and perforation, extracolonic or visceral injuries have also been described. Splenic rupture is a rare complication following colonoscopy, with few cases reported. We report a 60 -year-old female who presented to surgical consultation $8 \mathrm{~h}$ after a diagnostic colonoscopy. Clinical, laboratory and imaging findings were suggestive for a massive hemoperitoneum. At surgery, an almost complete splenic disruption was evident, and an urgent splenectomy was performed. After an uneventful postoperative period, she was discharged home. Splenic injury following colonoscopy is considered infrequent. Direct trauma and excessive traction of the splenocolic ligament can explain the occurrence of this complication. Many times the diagnosis is delayed because the symptoms are due to colonic insufflation, so the most frequent treatment is an urgent splenectomy. A high index of suspicion needs an early diagnosis and adequate therapy.
\end{abstract}

(C) 2008 The WJG Press. All rights reserved.

Key words: Colonoscopy; Splenic injury; Splenic rupture; Splenectomy

Peer reviewer: Burton I Korelitz, MD, Department of Gastroenterology, Lenox Hill Hospital, 100 East 77th Street, 3 Achelis, New York 10021, United States

Guerra JF, San Francisco I, Pimentel F, Ibanez L. Splenic rupture following colonoscopy. World J Gastroenterol 2008; 14(41): 6410-6412 Available from: URL: http://www.wjgnet. com/1007-9327/14/6410.asp DOI: http://dx.doi.org/10.3748/ wjg. 14.6410

\section{INTRODUCTION}

Colonoscopy is a safe and routinely performed diagnostic and therapeutic procedure for different large bowel diseases. The most common complications include bleeding (1\%) and perforation $(0.1 \%-0.2 \%)$, and the chance of complication increases if any therapeutic actions are added, such as polypectomy or dilation ${ }^{[1,2]}$. Extracolonic or visceral injuries, including pneumothorax, pneumomediastinum, acute appendicitis, retroperitoneal abscess and others, are far less common ${ }^{[3]}$. Splenic injury is a rare complication of colonoscopy with few cases described; the first one was reported in $1974^{[4]}$. Even when some patients with late presentation have been mentioned $^{[5,6]}$, most of them developed symptoms a few hours after colonoscopy, and the majority of them underwent emergency surgery. We report a case of splenic rupture following colonoscopy, treated with urgent splenectomy.

\section{CASE REPORT}

A 60-year old female, with no significant medical history, underwent a diagnostic colonoscopy in another center. During the procedure, two rectal polyps (5 $\mathrm{mm}$ each) were resected. It was not difficult to reach the ileocecal valve. Endoscopy was performed under intravenous sedation (midazolam, $5 \mathrm{mg}$ iv). She was observed in the recovery room for $2 \mathrm{~h}$ and then discharged home. Eight hours later, the patient came to our institution, complaining of diffuse abdominal pain and distension. On examination, she was pale, with a pulse rate of 100 beats per minute and her blood pressure was $103 / 52 \mathrm{mmHg}$. She had nonspecific abdominal tenderness, but no peritoneal signs. A colonic perforation after colonoscopy was suspected. The patient was resuscitated with vigorous intravenous fluid administration at the intermediate care unit. Her chest and abdominal $\mathrm{X}$-ray showed no free air (Figure 1). Blood tests showed a hematocrit of $18 \%$ (hemoglobin, $6 \mathrm{~g} / \mathrm{dL}$ ). After an adequate haemodynamic stabilization and transfusion of 3 units of packed red cells, an abdominal 


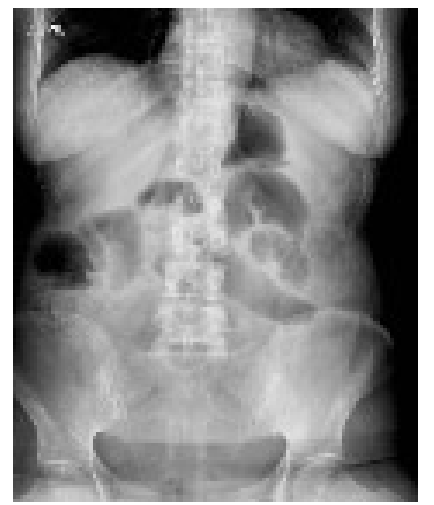

Figure 1 Abdominal X-ray showing no free air.

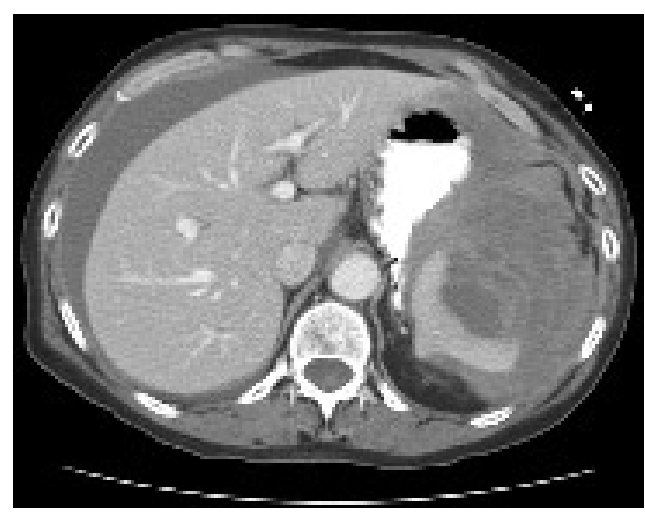

Figure 2 Hemoperitoneum and perisplenic hematoma.

CT scan demonstrated free fluid with a density suggesting blood, and a $12.5 \mathrm{~cm} \times 9.6 \mathrm{~cm}$ left subphrenic perisplenic hematoma (Figure 2). No pneumoperitoneum was evident. At laparotomy, about three liters of intraperitoneal blood, and an almost complete splenic disruption were evident, so a splenectomy was performed. There were no perisplenic adhesions. No colon wounds or tears were seen. The postoperative course was uneventful, and she was discharged home on postoperative day 4. Specimen histologic examination revealed nothing but haemorragic parenchyma and inflammatory response, without any underlying splenic disease.

\section{DISCUSSION}

Splenic injury following colonoscopy is considered very infrequent. Only 40 cases have been reported ${ }^{[3-15]}$. To our knowledge, our case is the first case coming from South America. We believe that this is a rare but, most of the times, an under published complication of colonoscopy, so the real incidence might be higher. Although no specific causes have been established, the mechanism of injury may be related to direct trauma or preferently, excessive traction on the splenocolic ligament, which results in evulsion of the splenic capsule and different grades of parenchymal disruption ${ }^{[3,5,7]}$. A polypectomy or a biopsy was performed in most of reported cases ${ }^{[8]}$. Splenomegaly, inflammatory bowel disease, pancreatitis and intrabdominal post-surgical adhesions have been mentioned as predisposing factors, due to a suspected decreased mobility between the spleen and $\operatorname{colon}^{[8-10]}$.
However, these are not constant findings at surgery ${ }^{[9]}$. The addition of external abdominal pressure during colonoscopy has also been proposed as a risk factor for the development of this complication ${ }^{[7,8]}$. Usually, the clinical presentation occurs within the first $24 \mathrm{~h}$ after colonoscopy ${ }^{[7,8]}$; but many times the diagnosis is delayed because the symptoms are attributed to colonic insufflation ${ }^{[3]}$. Finally, the diagnosis is made in a critically ill patient, with the onset of hypotension and acute anemia. There are also some reported cases with a late presentation (from more than $24 \mathrm{~h}$ to $10 \mathrm{~d}$ ) and mild symptoms ${ }^{[5,6]}$. CT scan is the imaging modality of choice ${ }^{[11,12]}$, which determines the extent of splenic damage, and demonstration of hemoperitoneum. This information, added to the clinical setting, may help decide on the therapeutic option. In most series, splenectomy is the most frequent treatment of choice ${ }^{[3-9]}$. Very few cases have been treated with transfusion of hemocomponents, broad spectrum antibiotics and close hemodynamic monitoring ${ }^{[10,13,14]}$. Another therapeutic action successfully described is splenic artery embolization ${ }^{[15]}$. The use of this "conservative" treatment must be in direct relation with the hemodynamic status of each case, and in the expertise of a multidisciplinary medical team. In our case, the patient was treated with an urgent splenectomy, and had an uneventful postoperative period.

We believe that this is an unusual and probably under reported complication of colonoscopy. As colonoscopy is performed widely in different centers, the medical team should be aware of the possibility of a splenic injury after colonoscopy and a high level of suspicion needs an early diagnosis and adequate treatment.

\section{REFERENCES}

1 Macrae FA, Tan KG, Williams CB. Towards safer colonoscopy: a report on the complications of 5000 diagnostic or therapeutic colonoscopies. Gut 1983; 24: 376-383

2 Schwesinger WH, Levine BA, Ramos R. Complications in colonoscopy. Surg Gynecol Obstet 1979; 148: 270-281

3 Espinal EA, Hoak T, Porter JA, Slezak FA. Splenic rupture from colonoscopy. A report of two cases and review of the literature. Surg Endosc 1997; 11: 71-73

4 Wherry DC, Zehner H Jr. Colonoscopy-fiberoptic endoscopic approach to the colon and polypectomy. Med Ann Dist Columbia 1974; 43: 189-192

5 Taylor FC, Frankl HD, Riemer KD. Late presentation of splenic trauma after routine colonoscopy. Am J Gastroenterol 1989; 84: 442-443

6 Merchant AA, Cheng EH. Delayed splenic rupture after colonoscopy. Am J Gastroenterol 1990; 85: 906-907

7 Janes SE, Cowan IA, Dijkstra B. A life threatening complication after colonoscopy. BMJ 2005; 330: 889-890

8 Ahmed A, Eller PM, Schiffman FJ. Splenic rupture: an unusual complication of colonoscopy. Am J Gastroenterol 1997; 92: 1201-1204

9 Al Alawi I, Gourlay R. Rare complication of colonoscopy. ANZ J Surg 2004; 74: 605-606

10 Tsoraides SS, Gupta SK, Estes NC. Splenic rupture after colonoscopy: case report and literature review. J Trauma 2007; 62: 255-257

11 Zenooz NA, Win T. Splenic rupture after diagnostic 


\section{ISSN 1007-9327 CN 14-1219/R World J Gastroenterol November 7, 2008 Volume $14 \quad$ Number 41}

colonoscopy: a case report. Emerg Radiol 2006; 12: 272-273

12 Johnson C, Mader M, Edwards DM, Vesy T. Splenic rupture following colonoscopy: two cases with CT findings. Emerg Radiol 2006; 13: 47-49

13 Heath B, Rogers A, Taylor A, Lavergne J. Splenic rupture: an unusual complication of colonoscopy. Am J Gastroenterol
1994; 89: 449-450

14 Rockey DC, Weber JR, Wright TL, Wall SD. Splenic injury following colonoscopy. Gastrointest Endosc 1990; 36: 306-309

15 Stein DF, Myaing M, Guillaume C. Splenic rupture after colonoscopy treated by splenic artery embolization. Gastrointest Endosc 2002; 55: 946-948

S- Editor Zhong XY L- Editor Wang XL E- Editor Lin YP 